\title{
Electrocutaneous stimulus setting for identification of the ascending nociceptive pathway
}

\author{
Huan Yang*, Jan R Buitenweg, Hil GE Meijer \\ From Twenty Second Annual Computational Neuroscience Meeting: CNS*2013 \\ Paris, France. 13-18 July 2013
}

\section{Background}

Malfunctioning of the ascending nociceptive pathway plays a key role in the development of chronic pain, e.g. central sensitization. In psychophysical experiments, subject's binary responses are measured during applying electrocutaneous stimulation. The stimulation delivers a square waveform parameterized by three temporal parameters, number of pulses (NoP), inter-pulse interval (IPI), pulse width $(\mathrm{PW})$, and amplitude of the current $\left(\mathrm{I}^{\mathrm{A}}\right)$. These are the input-output measurements of this pathway accounting for peripheral activation, firing rate, synaptic transfer and supraspinal activation (Figure 1A). The relevant neurophysiological parameters may reflect the state of nociceptive system. To provide sufficient information to get the values of these parameters, multiple combinations of the settings in stimulus parameters are required. The challenge is to develop a reliable algorithm to estimate the parameters and to find an optimal stimulus setting.

\section{Methods}

We model this pathway as a cascaded two leaky integrate-and-fire models followed by a nonlinear binary detector at the supraspinal level (Figure 1B). A white noise source presents at the output of neuronal activity. The model has five unknown parameters: two time constants $\left(\tau_{1}, \tau_{2}\right.$ [msec]), two compound gain-threshold parameters $\left(\alpha_{1}, \alpha_{2}\right)$ and standard deviation of the neuronal noise $\left(\sigma_{\varepsilon}\right)$. The multiple combinations of stimulus

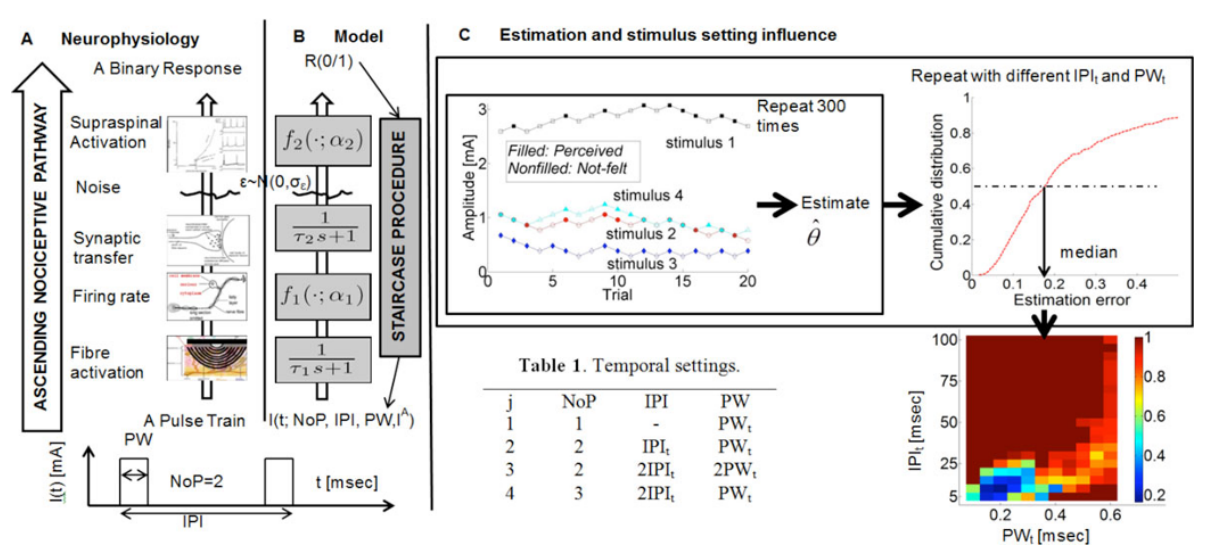

Figure 1 A: Neurophysiology of the ascending pathway; B: Model; C: Estimation and stimulus setting influence.

\footnotetext{
* Correspondence: h.yang-1@utwente.nl

Department of Mathematics, Electrical Engineering, Computer Science and

Mathematics, University of Twente, Enschede, Postbus 217, 7500 AE, the Netherlands
}

C 2013 Yang et al; licensee BioMed Central Ltd. This is an Open Access article distributed under the terms of the Creative Commons 
settings depend on two variables $\mathrm{IPI}_{t}$ and $\mathrm{PW}_{t}[\mathrm{msec}]$ (Table 1). Using each setting to generate an artificial dataset, we estimate the parameters by maximizing the likelihood function of these parameters and the stimulusresponse dataset. Varying $\mathrm{IPI}_{t}$ and $\mathrm{PW}_{\mathrm{t}}$, we look for an optimal setting of the stimulus.

\section{Results}

For each setting, we present estimation errors in a cumulative distribution with particular values of the parameters, $\theta=\left(\tau_{1}=0.2, \tau_{2}=20, \alpha_{1}=0.1, \alpha_{2}=0.04, \sigma_{\varepsilon}=0.005\right)$. The chance with an estimation error below $17 \%$ is a half when $\mathrm{IPI}_{\mathrm{t}}$ is 10 and $\mathrm{PW}_{\mathrm{t}}$ is 0.2 . Furthermore, we show the median of the estimation error in a $2 \mathrm{D}$ plot with varying $\mathrm{IPI}_{\mathrm{t}}$ and $\mathrm{PW}_{\mathrm{t}}$.

\section{Conclusions}

To identify the ascending nociceptive pathway, we have proposed an estimation approach using stimulus-response measurements. Optimal temporal settings of stimulus are found for a reliable estimation within the region of $\mathrm{IPI}_{t}$ 10-25 [msec] and $\mathrm{PW}_{\mathrm{t}}$ 0.15-0.4 [msec].

\section{Acknowledgements}

This research is supported by the Dutch Technology Foundation STW, which is part of the Netherlands Organisation for Scientific Research (NWO) and partly funded by the Ministry of Economic Affairs, Agriculture and Innovation.

Published: 8 July 2013
Submit your next manuscript to BioMed Central and take full advantage of:

- Convenient online submission

- Thorough peer review

- No space constraints or color figure charges

- Immediate publication on acceptance

- Inclusion in PubMed, CAS, Scopus and Google Scholar

- Research which is freely available for redistribution

Submit your manuscript at www.biomedcentral.com/submit
C Biomed Central 